\title{
Emergency Medical Service System: World and the Changing Indian Scenario
}

\author{
Samina Mufti, M.D., 'Showkat Ali Mufti M.D., M.R.C.P. ${ }^{2}$ \\ 'Departments of Hospital Administration \& ${ }^{2}$ Emergency Medicine, Sher-i-Kashmir Institute of Medical Sciences, Srinagar
}

\section{A B S T R A C T}

\begin{abstract}
Emergency Medical Service System(EMSS) is a specialty in which time is critical. Broadly, EMSS consists of pre-hospital care (synonyms, out of hospital care), emergency medical services and in-hospital care (popularly called emergency medicine). Dynamic as it is, EMSS is fast changing throughout the world. It may be in its infancy in India but change is imminent and can be perceived in many states and union territories where the pre-hospital care is becoming organized; life-support ambulances can be visualized on the roads. Medical Council of India's recent stand by permitting universities to start the MD course in Emergency Medicine and documenting the minimum standard requirements regarding infrastructure \& manpower for recognition are steps in the right direction. JMS 2012;15(2):101-105
\end{abstract}

Keywords: Emergency medical service, pre-hospital care, emergency medicine, emergency medical service system, emergency department, $\mathrm{MCl}$.

Burden of Emergencies shows an increasing trend globally and nationally. Emergencies in the developing Nations like India may be related to communicable disease such as diarrhea, malaria, tuberculosis, HIV; noncommunicable disease, like MI, stroke, cancers and accidents like road traffic crashes, poisonings, falls etc. Statistics indicate that annually 6,39,455 Indians die of cardiac emergencies $^{1} 1,42,309$ lives are lost in road traffic accidents ${ }^{2}$ 24,775 persons lose their lives due to poisoning. ${ }^{3}$ The World Health Organization has projected that by 2020 road traffic crashes will be a major killer in India, accounting for 546,000 deaths. ${ }^{4}$ Add to it the natural disasters like floods, cyclones earthquakes, tsunamis etc affecting various parts of the country almost every year. Manmade disasters like radiation

\section{Correspondence:}

Dr. Samina Mufti, MD,

Department of Hospital Administration, Sher-i-Kashmir Institute of Medical Sciences, Srinagar, 190011

E-mail:mufsamari.7091@gmail.com leaks, warfare, terrorism, building collapses, train-crashes etcetra are always a lurking threat. Many people who suffer various kinds of medical emergencies do not reach the hospital in time. Thirty percent of emergency patients in India die before they reach a hospital ${ }^{5}$ and about $80 \%$ do not reach within the first hour. ${ }^{6}$ If they escape death due to this delay, many among them may become disabled in the least. Consequently a negative emotional, socioeconomic and healthcare impact occurs on the person (if he/she survives) family in particular, society and nation in general.

\section{EMSS around the world}

"Emergency Medical Services System" refers to a comprehensive integrated public safety and health care system model. It consists of mechanisms for accessing the system and reporting an emergency; pre-hospital service delivery and transport mechanisms; definitive, specialty, and rehabilitative care facilities; public education, participation, and prevention processes; educational programming and 
institutions; integrated medical and administrative direction and oversight organizations and processes; resource allocation and financing structures; coordinating the role of collaborating organizations; etc. 'It also includes the management of disasters and crisis response.

\section{Pre-hospital care (EMS): Global picture}

It refers to the delivery of medical care at the site of the adverse medical event and en-route to a competent healthcare facility, usually in response to a call to a dispatch center that is able to provide medical advice to the caller and, if necessary dispatch an appropriate response (fire, police, medical). Emergency Medical Service(EMS) models vary through countries and even states. The EMS services in USA are usually under federal control run by police, fire and medical departments or by voluntary agencies. A uniform call number 911 connects the person to the dispatch center. The number is locked so that contact may not be lost in case the person falls unconscious. The ambulances are standardized. The personnel on the ambulances are trained and certified as Emergency Medical Technician Basic (EMTBasic) and the more advanced EMT-Paramedic (trained in advanced life support). Helicopter ambulances are equipped with critical care support and personnel for inter-hospital transfer of critical patients and pre-hospital care in difficult or far off terrain. All European countries have declared that citizens have access to emergency call number 112 which is usually the integrated dispatch center. It ensures right resources at the right time whether it is security, fire services or medical help. In case of Medical dispatch it is worth mentioning that in order to make the best use of resources, a two-tier system has been set up in most European countries and consists of emergency medical technicians or nurses as the first tier, and mobile intensive-care units as the second tier. A Real time connectivity exists between EMS and the inhospital ICU/ED. Among the Asian countries Singapore's EMS service is run by the SCDF (Singapore Civil Defense Force), which currently operates 46 ambulances based in 15 fire stations and 14 satellite stations in a single tier system. Emergency ambulance patients are delivered to 7 major public hospitals in the country that are equipped with modern Emergency Departments(ED). Singapore EMS is activated by a universal, centralized, enhanced ' 995 ' dispatching system run by the SCDF utilizing Computer Aided Dispatch, Medical Dispatch Protocols, Global Positioning satellite (GPS), Automatic Vehicle Locating Systems and Road Traffic Monitoring Systems. Ambulance in Singapore have been manned by specifically trained paramedics who undergo an 18 months training including theory, hospital and ambulance attachments They are able to provide Basic Life Support and defibrillation and some advanced life support treatments like laryngeal mask airway insertion, intravenous fluids, adrenalin, dextrose, nebulized salbutamol, aspirin, nitroglycerin, diazepam for seizures, oxytocin etc. $^{8}$

\section{In-hospital Care: Global picture}

In-hospital emergency medical services (IN-H-EMS) or Emergency Medicine (EM) refers to all those subsets of medical institutions and hospitals that have the capacity to deliver uninterrupted emergency care on a 24 hours a day, 7 days a week basis. These are Level 1 hospitals referred to in the Joint Commission on Accreditation of Hospitals (JCAHO) categorization of Emergency Care Hospitals. ${ }^{8}$ Emergency care is provided in the Emergency Departments(ED) of the hospitals where all the resources in the form of physical facility, manpower, equipment and machinery are pooled for appropriate patient care, manpower training and research. A well planned ED consists of a reception/registration, triage area, resuscitation and acute care area, procedure room, operation theatres, plaster room equipped with all the lifesaving and essential equipment, drugs and manpower expertise. It also consists of auxiliary and ancillary areas, conference/teaching rooms, staff rest rooms and patient's relative waiting space. All these are functionally sequenced. In some hospitals the areas are color coded for the triaged patients. Although comprehensive Emergency Medical Systems(EMS) have been prevalent in Europe and Americas for last 5-6 decades however some global issues continue to prevail. Crowding in EDs is an issue prevalent internationally, inspite of departments being very well planned and designed. The causes effects and remedies have been studied intensively. ${ }^{10}$ It is only recently that operations research models like queuing theory have been applied.

\section{Training in Emergency Medicine: Global picture}

Emergency Medicine is an inter-disciplinary specialty, one which is interdependent with all other clinical disciplines. It encompasses the achievement of a large body of specific knowledge that requires indepth studies; the development of complex and advanced technologies for diagnosis and treatment in emergencies; and a perceived need of the health services community that requires specific emergency medicine(EM) competencies and responsiveness to emergencies. This resulted in the birth of various training programmes in EM, however the courses and the curricula across nations and even within are as varied as the nomenclature of ED. Attempts to standardize the courses and curricula are ongoing at the international and national levels. International Federation for Emergency Medicine (IFEM) convened a committee of international physicians, health professionals, and other experts in emergency medicine and international emergency medicine development to outline a curriculum for training of specialists in emergency medicine. ${ }^{11}$

EuSEM first published a European Core Curriculum for Emergency Medicine in 2002. The new and expanded version of the Curriculum presents a guideline for the development and organization of recognized training 
programmes of comparable standard across Europe. The document was developed by a Curriculum Task Force of EuSEM and has been reviewed, amended and approved by the Multidisciplinary Joint Committee of the Union Européenne des Médecins Spécialistes (MJC-UEMS). ${ }^{12}$

In the United States, the Accreditation Council for graduate Medical education(ACGME) and the Residency Review Committee (RCC) for Emergency Medicine govern training in Emergency Medicine. The residency, usually of three years duration, is designed to prepare physicians for the everyday practice of EM. Residents are trained under qualified faculty to develop clinical maturity, judgement, technical skills and a knowledge base in the fundamentals of EM. Basic areas of expertise for an emergency physician(EP) include resuscitation, airway management, supervision of pre-hospital systems and the provision of care ranging from initial to definitive for the complete spectrum of medical illness, poisoning, and injury in all age groups. ${ }^{5}$ The residency programs based in institutions with adequate requisite resources are headed by Program Directors with specific qualifications, authority and leadership capabilities. Full time Faculty devotes sufficient time to teaching and scholarly activity. Duration of the EM course varies from country to country from as low as two years to six years.

\section{EMSS in India}

Pre-hospital care in India presented a bleak scenario in the recent past. In India in-hospital emergency care is usually provided in crowded emergency departments, called casualties in the public hospitals. The patients are received, assessed and managed by the most junior doctors called junior residents or general duty medical officers, although in teaching hospitals postgraduate senior residents of medicine or surgery are also posted in the emergency room. The resources in terms of space, equipment, beds etc are inadequate, planned several decades back. The infrastructure and manpower supply has failed to keep pace with the growing burden of emergency patients. The ambulances are not standardized, Institutions and trainings are not regulated in terms of trainings and courses.

The private hospitals are hesitant to deal with emergencies either due to paucity of infrastructure, reluctance to wave off charges or unwillingness to deal with medico-legal cases. The Supreme Court has been emphatic in declaring that the fundamental right to life covered within its scope the right to emergency healthcare. (Parmanand Katara v. Union of India: Supreme Court, 1989, Paschim Banga Khet Mazdoor Samity v. State of West Bengal, Supreme Court, 1996, Pravat Kumar Mukherjee v. Ruby General Hospital \& Others, National Consumer Disputes Redressal Commission, 2005). In 2006, the Law Commission looked into the issue, and from a comparative study of the legislations in other countries (Emergency Medical Treatment and Labour Act: EMTALA and Consolidated Omnibus Budget Recon- ciliation Act: COBRA of USA.) suggested a legal right to emergency medical care, reiterating that concerns like legal formalities, monetary considerations or even the infrastructure restraints of the institutions should not stand in the way of providing basic and emergency medical treatment. ${ }^{13}$ Despite the very unambiguous reiteration of the right to emergency health care by the Courts, the legal framework has not been developed sufficiently to give effect to this right.

\section{The transition}

India is awakening to the realization of standardization in the EMSS ranging from a National Ambulance Code to the development of a uniform curricula for well regulated training courses.

\section{Pre-hospital Care}

The ambulances which were simply transport vehicles are now lifesaving vehicles It is quiet exciting to see 108/102 ambulances fitted with GPS and life support infrastructure on the Indian roads move patients in distress to the healthcare facilities. These ambulance services resourced with pre-hospital care facilities were started as a public private partnership (PPP) between Satyam computers ltd and the government of Andhra Pradesh, where the services are presently operated by GVK EMRI (Emergency Management Research Institute). ${ }^{14}$ Second to adopt the model was Gujarat. Currently comprehensive EMS is operational in fifteen Indian states and under process in another six states (Table 1). Competitive tender bidding has introduced new players like Ziqita Health Care in some states like Punjab, Bihar and Odisha. In states like Odisha and Madhya Pradesh maternal transport and some other emergency transfers are done using a low cost model called Janani Express. The Centralized Accident Trauma Service (CATS) which began

\section{TABLE 1: Status of EMS in India}

\begin{tabular}{|c|c|c|c|}
\hline S.No & $\begin{array}{l}\text { States where EMS is } \\
\text { operational } \\
\text { (year of initiation) }\end{array}$ & $\begin{array}{l}\text { States where EMS is } \\
\text { under process }\end{array}$ & $\begin{array}{l}\text { States where EMS i } \\
\text { is not operational }\end{array}$ \\
\hline 1. & Andhra Pradesh (2005) & Delhi-National Capital Territory & Arunachal Pradesh \\
\hline 2. & Gujrat (2007) & Jammu \& Kashmir & Haryana \\
\hline 3. & Madhya Pradesh (2007) & Jharkhand & Manipur \\
\hline 4 & Uttarakhand (2008) & Maharashtra & Mizoram \\
\hline 5. & Rajasthan (2008) & Odisha & Nagaland \\
\hline 6. & Tamil Nadu (2008) & Uttar Pradesh & Sikkim \\
\hline 7. & Goa (2008) & & Tripura \\
\hline 8. & Assam (2008) & & West Bengal \\
\hline 9. & Karnataka (2008) & & \\
\hline 10. & Meghalaya (2008) & & \\
\hline 11. & Bihar (2009) & & \\
\hline 12. & Chattisgarh (2010) & & \\
\hline 13. & Himachal Pradesh (2010) & & \\
\hline 14. & Kerela (2010) & & \\
\hline 15. & Punjab (2011) & & \\
\hline
\end{tabular}


even earlier in the 1984 in Delhi is in the process of expanding and modernizing its ambulance fleet.

Some NGOs (non-governmental organizations) and private hospitals in cities and states have constructed their own EMS setups. Principal among these are the National Network of Emergency Services (NNES), Ahmedabad, Delhi, Pune, Hyderabad, Chennai, Raipur, Ranchi, and Kolkata; Life Support Ambulance Service (LSAS), Kerala, Mumbai; Operation Sanjeevani, Bengaluru; Ambulance Access for All (AAA), Mumbai; Indian Institute of Emergency Medical Services (IIEMS), Kerela, ${ }^{15}$ etc. What is lacking is a uniform call number and ambulance standardization.

\section{In-hospital Care}

Today, well-equipped EDs have cropped up all over the country, and many of these centers are headed by physicians who have formally trained in emergency medicine through trainings offered by foreign collaboration. The ED of Appolo Hospital Hyderabad is JCI(Joint Commission Internationale) accredited. Other hospitals must at least aim for accreditation by NABH (National Accreditation Board of Hospitals). The ED design should aim to achieve the following functional flow (Figure 1).

The scenario of EM in India prompted supporters whether individuals, professional bodies, societies and Institutes to advocate the development of Emergency Medicine as a distinct academic discipline. Society of Emergency Medicine, (SEMI) Lifeline Foundation, IndoUs Joint Working Group(INDUS), EMRI are some examples of the staunch supporters of EM. SEMI has always highlighted the need for academic Emergency Medicine in various forums including annual conferences. It has also submitted earnest reminders to the MCI for start of MD course in EM. The lack of specialist training in the field was one of the principal issues highlighted by the white paper on Indian emergency medicine published by the INDUS collaboration.

Understanding the need for EM as a separate discipline MCI recognized MD in EM as the 30th specialty in july 2009 and subsequently in 2010, a specialty Board in EM was constituted by its Board of Governors. MCI is currently finalizing the curriculum of EM. Till date MCI has granted permission to thirteen university hospitals to start three year MD course in EM, which are government, private or trust owned. $^{16}$ All India Institute of Medical Sciences has also started the course. MCI has also recognized the MCEM degree courses and also set guidelines for faculty development in EM and minimum qualifications for teaching faculty. Although substantial these positive steps are just not enough to meet the huge demand gap which is 12000 EPs at present. ${ }^{17}$ Many hospitals in India run collaborative courses with foreign backup. It would be worthwhile to explore the possibility of providing MCI recognition for accredited courses to fill in the huge gap. AHA accredited/approved courses in life support are also offered by many institutes and agencies. EPs, other doctors, paramedics and nurses should periodically update their resuscitation and life support skills.

\section{Legislation}

Hospitals fall within the State list, and therefore, a central act cannot be legislated. However a model bill drafted by the Law Commission will serve as a template for the states and union territories. The bill recommends that hospitals and medical practitioners would need to initially screen

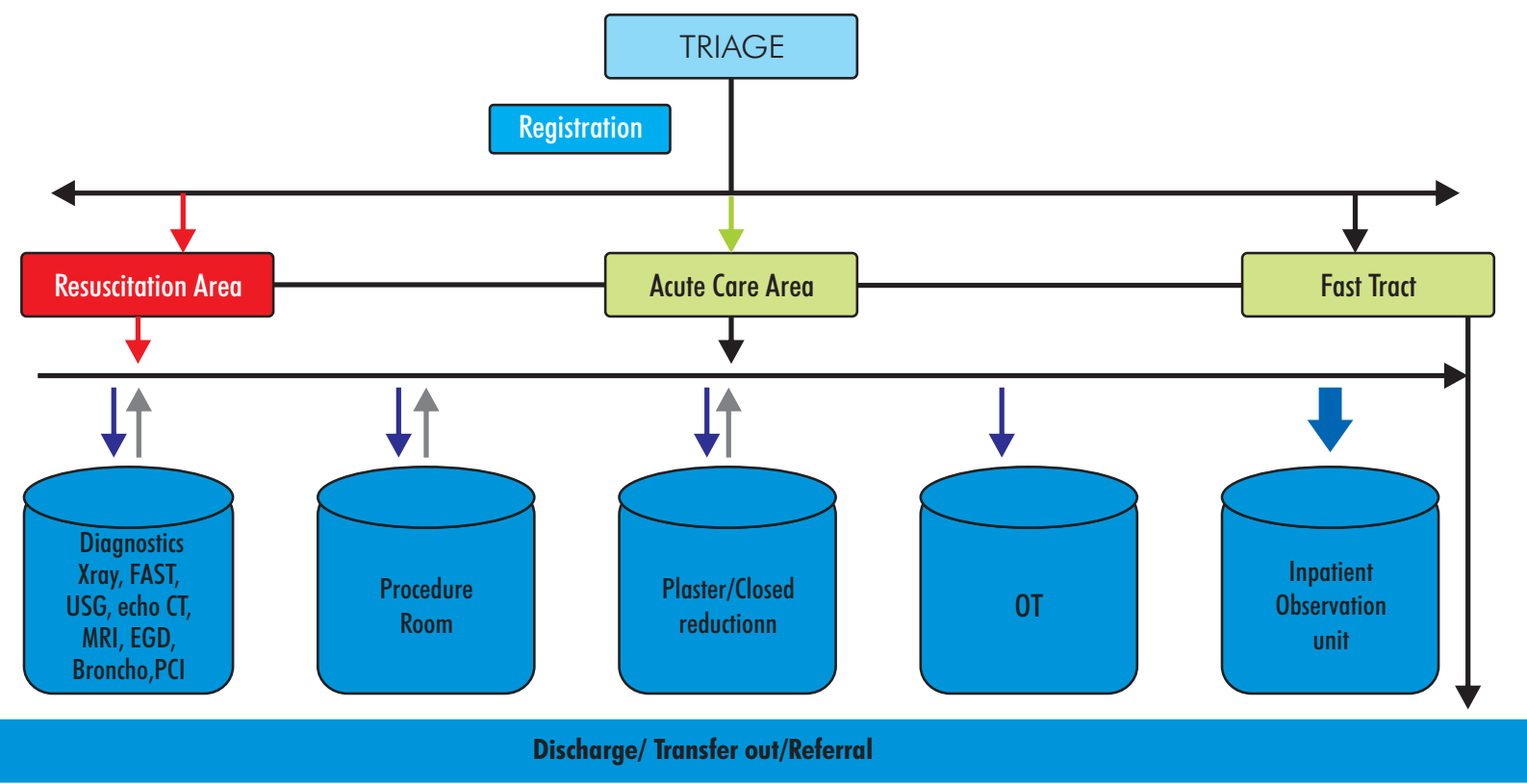

FIGURE 1: Functional flow in the Emergency Medicine Department 
patients to determine if they require emergency medical treatment, and if they do, refusing such treatment without justifiable reason would amount to an offence. After ensuring stabilization, the patient may be transferred to a better equipped facility for further management. Gujrat state has enacted the legislation. Other states can take the cue.

Since Health care in India is a state subject delivered mostly through Public Institutions the state must play a major role in providing better emergency medical care to its people. The Country looks forward to the MCI, National Accreditation Board(NABH) and the National Highway authority as central agencies for standardizing, regulating and bringing uniformity to all the components of EMSS. Public Private Partnerships have shown promise in the prehospital care and may extend to other components of EMSS. To sum up a healthy and dynamic EMSS is the need of the hour to avoid death and disability for want of it.

\section{Acknowledgement:}

Authors are grateful to Dr. Owais Mushtaq Shah, Jr. Resident, Department of Hospital Administration (Trust Hospital), SKIMS, Srinagar for his help.

\section{References}

1. International Cardiovascular Disease Statistics, American Heart association www.americanheart. org, 2004.

2. Fitzgerald M, Dewan Y, O'Reilly G, Mathew J, McKenna C. India and the management of road crashes: Towards a national trauma system. Indian J Surg 2006;68:226-32.

3. National Crime Records Bureau, New Delhi. Accidental Deaths and Suicide in India 1999.

4. Peden M, Scurfield R, Sleet D, Mohan D, Hyder AA Jarawan E, et al. World Report on Road Traffic Injury Prevention. Geneva WHO;2004.

5. Das AK, Gupta SB, Joshi SR, et al. White paper on academic emergency medicine in India: INDO-US Joint Working Group (JWG). J Assoc Physicians India 2008;56:789-798.

6. Ramanujan P, Aschkenasy M. Identifying the need for prehospital and emergency care in the developing world: A case study in Chennai, India. J Assoc Physicians India 2007;5.

7. Emergency Medical Services Systems in the European Union: report of an assessment project coordinated by the World Health Organization. Copenhagen: Who Regional Office for Europe; 2008. [cited 2009 July 8]. Available from: http://www.euro.who.int/__ data/assets/pdf_file/0016/114406/E92038.pdf (last accessed 10 December 2012).

8. www.slideshare.net/narenthorn/ems-in-singaporepresentation-585203

9. www.emergencymedicine.in/Institutions/Category. htm.

10. Nathan R. Hoot, Dominik Aronsky. Systematic Review of Emergency Department Crowding Causes, Effects, and Solutions. Ann Emerg Med 2008;52:126-136.

11. Cherri Hobgood, Chapel Hill, NC Venkataraman Anantharaman et al. International Federation for Emergency Medicine model curriculum for emergency medicine specialists. CJEM 2011;13:109-121

12. European Curriculum for Emergency Medicine. A document of the EuSEM Task Force on Curriculum approved by the Council of the European Society for Emergency Medicine and by the UEMS Multidisciplinary Joint Committee on Emergency Medicine. Final Draft (January 2009) Curriculum Committee Chair.

13. Law commission of India 201st report on emergency medical care to victims of accidents and during emergency medical condition and women under labour. August 2006.

14. Vijay Kumar Reddy, Public Private Partnership for scaling up of EMS across India EMS India Jan 2012 18th issue p2-6,11www.emsindia.

15. Emergency care in India: the building blocks Imron Subhan, Anunaya Jain.

16. http//www.mciindia.org/InformationDesk/Colleges Courses Search.

17. Subroto Das. Mind the Training Gap. Emergency Physicians International 2012;7:8. 